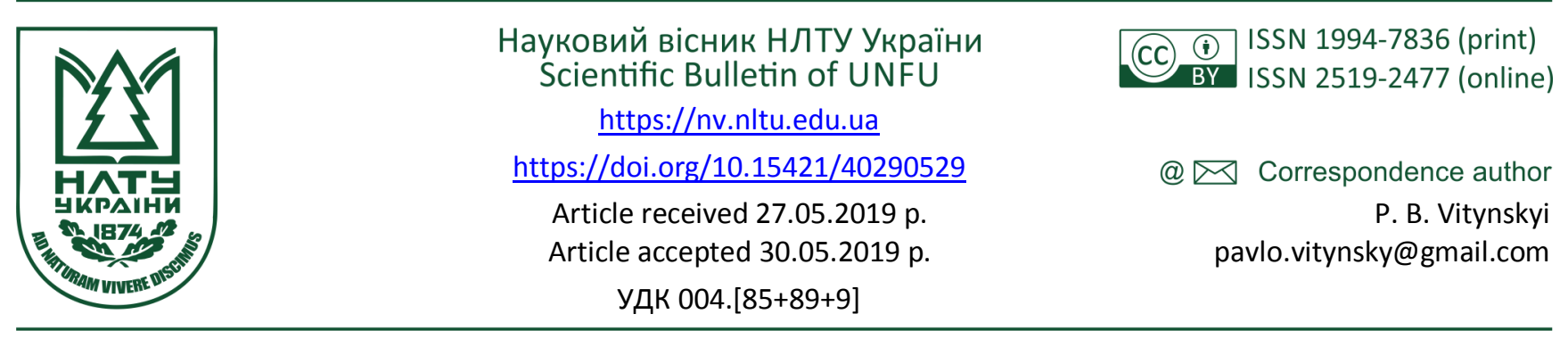

П. Б. Вітинський, Р. О. Ткаченко

Національний університет "Львівська політехніка", м. Львів, Україна

\title{
НЕЙРОПОДІБНА СТРУКТУРА ДЛЯ ЗАДАЧ ПРОГНОЗУВАННЯ В УМОВАХ КОРОТКИХ ВИБІРОК ДАНИХ
}

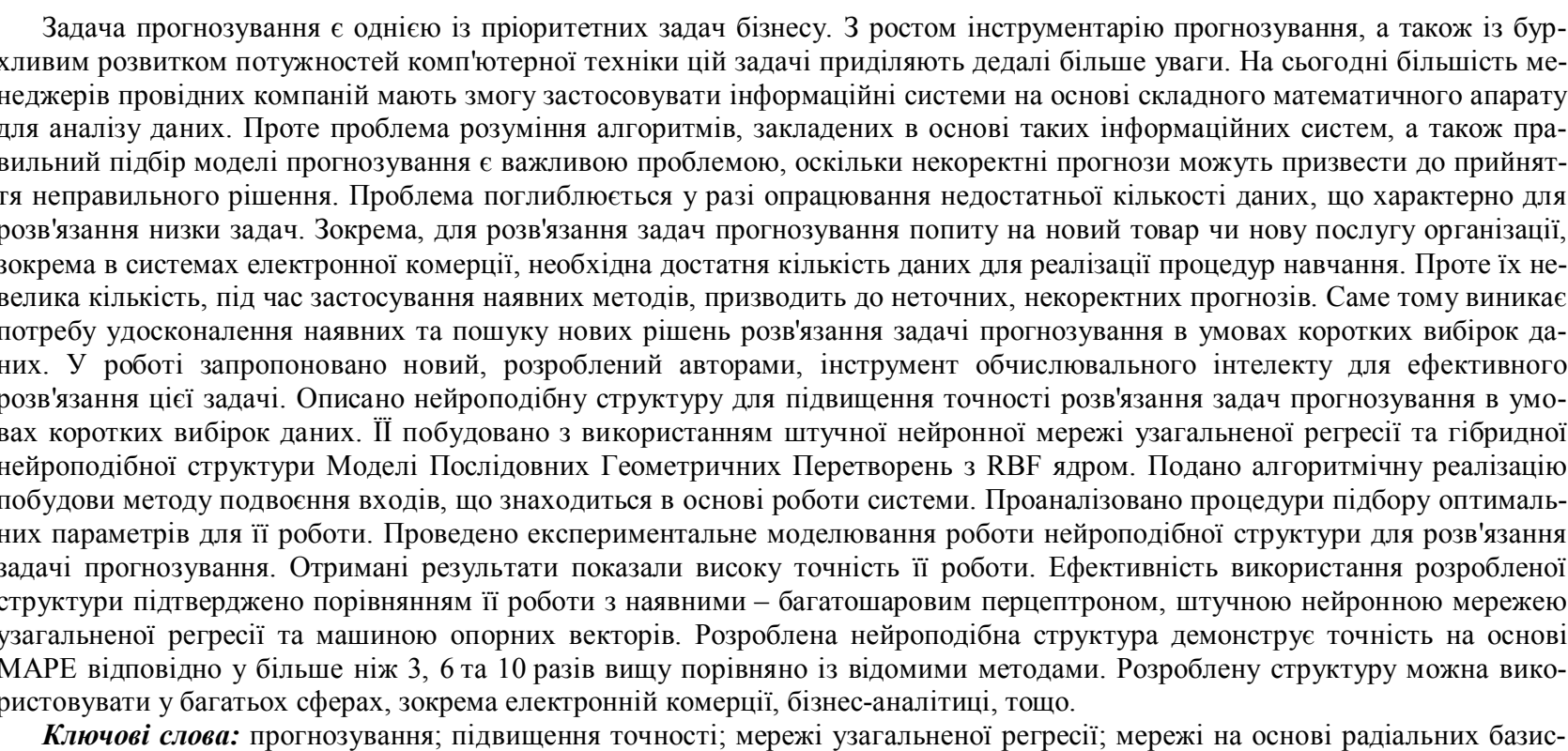
них функцій; нейроподібні структури МПГП.

Вступ. Ефективне розв'язання задачі прогнозування $€$ критичним у стратегічному плануванні бізнесу. Прийняття більшості бізнес-рішень менеджерами організацій відбувається на основі прогнозних даних (Bandara et al., 2019). Точний та надійний прогноз цільового показника необхідний для забезпечення:

- можливості визначення майбутніх перспектив розвитку компанії;

- зменшення, а в деяких випадках, уникнення потенційних ризиків для компанії чи виробництва;

- можливість використання ресурсів компанії на повну потужність тощо.

Стрімкий розвиток інфраструктури бізнес-середовища зумовлює потребу урахування дедалі більшої кількості чинників у побудові правильної моделі прогнозування. Саме доступні дані та їх характеристики $€$ найважливішими ознаками для побудови такої моделі.
На перший погляд, в еру Великих Даних, вибір доцільної інформації, в основному на основі історичних даних, для побудови моделі прогнозу здається простою задачею. Проте інколи виникають ситуації коли таких даних не вистарчає через низку причин. Наприклад, для оцінювання та прогнозування попиту на новий товар чи нову послугу організації, історичних даних майже немає (Lin et al., 2013). Для прогнозування різноманітних властивостей новостворених матеріалів у матеріалознавстві, де проведення експерименту (спостереження) потребує величезних матеріальних (Tepla et al., 2018) або часових (Izonin et al., 2018) затрат, необхідну їх кількість також важко назбирати. Існує чимало подібних прикладів. У цьому випадку актуальною задачею $є$ ефективне опрацювання наявних історичних даних для отримання якісного прогнозу.

У (Khaikin, 2006) розглянуто задачу прогнозування

\section{Інформація про авторів:}

Вітинський Павло Богданович, аспірант, кафедра інформаційних технологій видавничої справи. Email: pavlo.vitynsky@gmail.com; https://orcid.org/0000-0002-3183-3596

Ткаченко Роман Олексійович, д-р техн. наук, професор, завідувач кафедри інформаційних технологій видавничої справи. Email: roman.tkachenko@gmail.com; https://orcid.org/0000-0002-9802-6799

Цитування за ДСтУ: Вітинський П. Б., Ткаченко Р. О. Нейроподібна структура для задач прогнозування в умовах коротких вибірок даних. Науковий вісник НЛТУ України. 2019, т. 29, № 5. С. 147-150.

Citation APA: Vitynskyi, P. B., \& Tkachenko, R. O. (2019). Nural-like Structure for Forecasting in the Conditions of Short Data Samples. Scientific Bulletin of UNFU, 29(5), 147-150. https://doi.org/10.15421/40290529 
у випадку коротких вибірок даних із використанням багатошарового перцептрону. У роботі показано невисоку точність прогнозування. Автор відзначив можливість збільшення точності прогнозу в разі використання більшої кількості даних. Окрім цього, серед недоліків такої моделі варто відзначити також довготривалий, ітеративний процес навчання нейромереж цього типу. У роботі (Tkachenko \& Izonin, 2018) описано новий тип нейронних мереж прямого поширення з неітеративним машинним навчання на основі Моделі послідовних Геометричних Перетворень (МПГП) для розв'язання задач регресії. Основною перевагою такого інструменту обчислювального інтелекту є висока швидкість реалізації процедури навчання. У роботі (Vitynskii et al., 2018) подано процедуру розширення вхідного шару нейроподібних структур МПГП членами полінома КолмогороваГабора задля підвищення точності розв'язання задач прогнозування. Очевидним недоліком такого підходу є значне зростання часу навчання нейроподібних структур зі збільшенням степеня цього полінома. У роботі (Tkachenko \& Kutucu, 2018) запропоновано новий спосіб розширення вхідного шару нейроподібної структури за рахунок використання RBF функцій. Це дало змогу значно підвищити точність роботи такої мережі за задовільних характеристик тривалості процедур навчання. Незважаючи на це, жоден 3 перелічених інструментів не забезпечує достатньої точності під час розв'язання задачі прогнозування в умовах коротких вибірок даних.

Саме тому метою роботи є розроблення гібридної структури обчислювального інтелекту для підвищення точності розв'язання задачі прогнозування в умовах коротких вибірок даних та дослідження її ефективності.

Метод опрацювання коротких вибірок даних підвищеної точності. Нехай вхідні дані представлено матрицею такого вигляду:

$$
\left(\begin{array}{ccccccc}
x_{11} & x_{12} & x_{1 j} & & \ldots & x_{1 N} & y_{1} \\
x_{21} & x_{22} & x_{2 j} & & \ldots & x_{2 N} & y_{2} \\
x_{i 1} & x_{i 2} & x_{i j} & & \ldots & x_{i N} & y_{i} \\
\ldots & \ldots & \ldots & \ldots & \ldots & \ldots \\
x_{K j} & x_{K 2} & x_{K j} & \ldots & x_{K N} & y_{K} \\
x_{K+1,1} & x_{K+1,2} & x_{K+1, j} & \ldots & x_{K+1, N} & y_{K+1} \\
\ldots & \ldots & \ldots & \ldots & \ldots & \ldots \\
x_{T 1} & x_{T 2} & x_{T j} & \ldots & x_{T N} & y_{T}
\end{array}\right),
$$

де: $x_{i, j}, i=\overline{1, K}, j=\overline{1, N}-$ вхідні дані для навчання; $y_{i}, i=\overline{1 . . K} \quad-\quad$ вихідні дані для навчання; $x_{i, j}, i=\overline{K+1, T}, j=\overline{1, N}-$ вхідні дані для тестування; $y_{i}, i=\overline{K+1, T}-$ невідомі вихідні тестові дані.

Процедура навчання. У режимі навчання для кожного $m$-го вектора, де $m=\overline{1, K}$ знаходимо:

1) Гаусівські віддалі $G_{m, k}$ до всіх тренувальних векторів, $x_{k, 1}, \ldots, x_{k, j}, \ldots, x_{k, n} ; y_{k}$ включаючи обраний вектор:

$$
G_{m, k}=\exp \left(\frac{E_{m, k}^{2}}{2 \sigma^{2}}\right), k=\overline{1, K} .
$$

Для $m=k$ маємо $G_{m, k}=1 ; \sigma$ - параметр функції Гауса, який підбирається експериментально.

2) Обчислюємо для всіх можливих пар векторів $z_{t, k}=y_{m}-y_{k}$ :

$$
W_{m, k}=z_{m, k} \cdot G_{m, k}, m=\overline{1, K}, k=\overline{1, K} .
$$

Для $k=t$ маємо $W_{m, k}=0$. Формуємо $k^{2}$ векторів 3 подвоєними входами:

$$
\begin{gathered}
x_{m, 1}, \ldots, x_{m, j}, \ldots, x_{m, n}, x_{k, 1}, \ldots, x_{k, j}, \ldots, x_{k, n} \rightarrow W_{t, k}, \\
m=\overline{1, K}, k=\overline{1, K} .
\end{gathered}
$$

Використовуючи $K^{2}$ векторів 3 подвоєними входами (5), навчаємо гібридну RBF мережу на основі нейроподібних структур Моделі Послідовних Геометричних Перетворень. Її топологію подано на рис. 1.

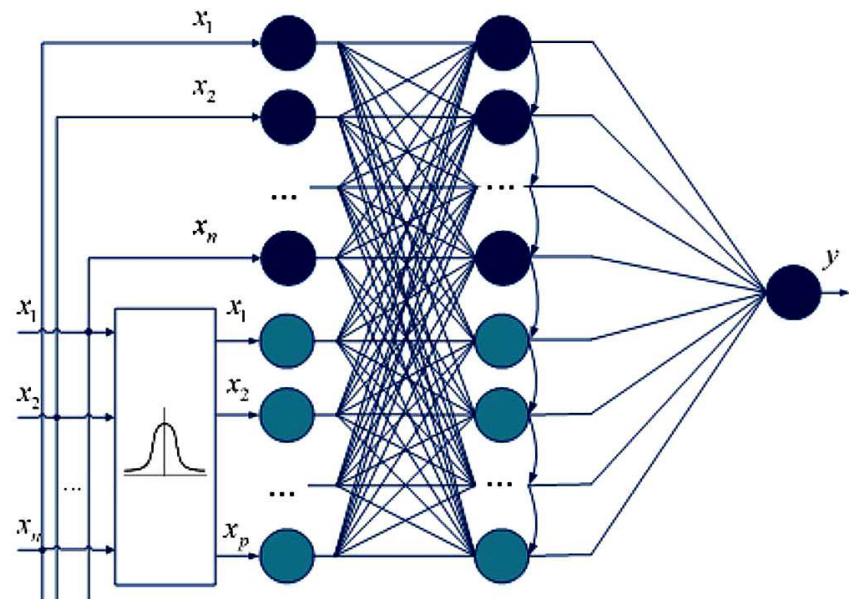

Рис. 1. Топологія гібридної RBF мережі на основі нейроподібних структур МПГП

Деталі алгоритмів навчання та функціонування цього інструменту обчислювального інтелекту подано у (Tkachenko \& Kutucu et al., 2018).

Процедура застосування. У режимі функціонування, для рухомої точки виконуємо обчислення згідно 3 GRNN:

$$
y G_{t}=\sum_{m=1}^{K} G_{t, m} \cdot y_{m} / \sum_{m=1}^{K} G_{t, m}, t=1,2, \ldots .
$$

У випадку, якщо $\sum_{m=1}^{K} G_{t, m}<10^{-6}$, то приймаємо, що

$$
\sum_{m=1}^{K} G_{t, m}=10^{-6} .
$$

Застосовуючи навчену, гібридну RBF мережу з подвоєними входами, здійснюємо $K$ прогнозувань виду $x_{t, 1}, \ldots, x_{t, j}, \ldots, x_{t, n}, x_{m, 1}, \ldots, x_{m, j}, \ldots, x_{m, n} \rightarrow W_{t, k}$, для $m=\overline{1, K}$, a компоненти $x_{m, 1}, \ldots, x_{m, j}, \ldots, x_{m, n}$ представлені вхідними компонентами тренувальних векторів.

Як досліджено у (Tkachenko et al., 2018), ефективне функціонування гібридної RBF-мережі потребує налаштування таких параметрів:

- вибір центрів $\sigma$ радіальних функцій: переважно кількість центрів більша, ніж кількість входів. Центри - це випадкова вибірка з векторів навчальних даних.

- вибір $\delta$, яка $\epsilon$ параметром розмаху гаусівської функції. Найпростіший варіант - вибрати спільне $\delta$ для всіх центрів $\mathrm{RBF}$. Варто зазначити, що в умовах нерівномірного представлення даних, такий вибір не забезпечує необхідної точності.

Остаточне значення прогнозованого виходу $y_{t}^{\text {pred }}$ обчислюємо за такою формулою:

$$
y_{t}^{\text {pred }}=y G_{t}+\sum_{m=1}^{i} W_{t, m} / \sum_{m=1}^{i} G_{t, m}, t=1,2, \ldots .
$$

Описаний алгоритм повторюється для всіх тестових $t$ векторів.

Моделювання та результати, опис даних. Для перевірки правильності побудови алгоритмічного рішення та оцінки ефективності роботи розробленої структу- 
ри розглянемо приклад апроксимації нелінійної функції двох змінних (Хайкін, 2006):

$$
F(x, y)=\left(1-x^{2}\right)+2(1-y)^{2} .
$$

Візуальне представлення функції на проміжку [$10000,10000]$ подано на рис. 2. Обмежимо діапазон зміни змінних $x, y$ інтервалом $[-1 ; 1]$. Для навчання структури використаємо вибірку з 20 векторів. Тестова вибірка містить 10 векторів даних. Оцінювання результатів роботи розробленої гібридної системи відбувалося із використанням середньої абсолютної похибки у відсотках MAPE (Mean Absolute Percentage Error):

$$
\text { MAPE }=\frac{100}{n} \sum_{i=1}^{n}\left|\frac{y_{i}^{\text {pred }}-y_{i}^{\text {true }}}{y_{i}}\right| \text {, }
$$

де $y_{i}^{\text {true }}$ - фактичне, а $y_{i}^{\text {pred }}-$ отримане значення для $i$ го вектора.

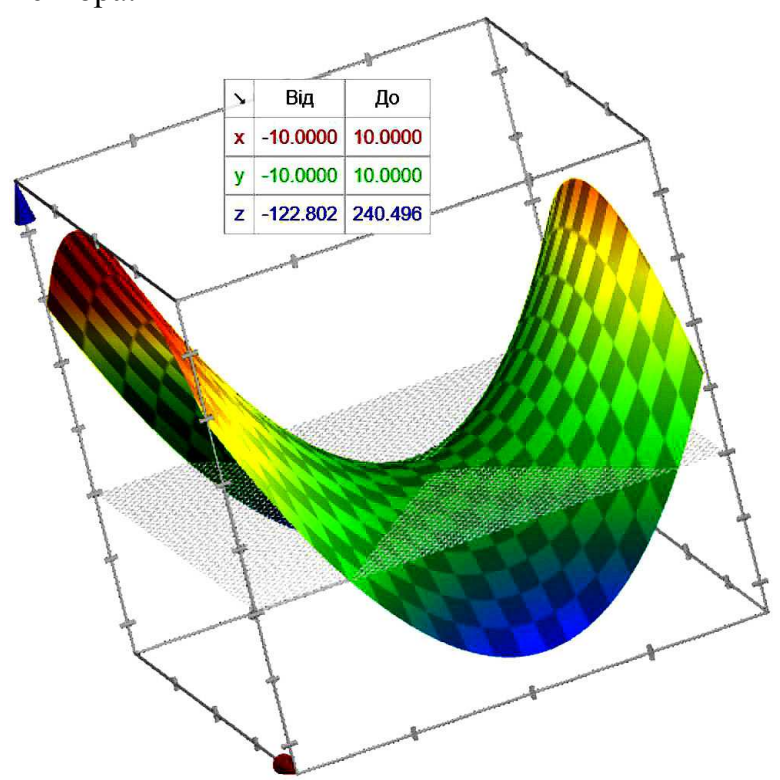

Рис. 2. Візуальне представлення функції (8)

Програмне рішення. Тестування роботи розробленої системи відбувалося на розробленому авторами програмному рішенні. Архітектуру програмної реалізації гібридної нейроподібної структури побудовано з використанням концепції "Модель-Представлення-Контролер", згідно з якою функціонал роботи системи відділяється від візуального відображення даних у різні класи. Усі класи спроектовано зі зручним API, яке дає можливість повторного використання та їх інтеграцію в

\begin{tabular}{|c|c|c|}
\hline Data Mining & & $\square$ \\
\hline \multicolumn{3}{|c|}{ Гібридна нейромережа GRNN-RBF } \\
\hline \multicolumn{2}{|c|}{ Обрати файл для навчання } & Обраги файл для тестування \\
\hline \multicolumn{3}{|l|}{ Налаштування } \\
\hline \multicolumn{2}{|l|}{ V. Режим test } & $\square$ Режим use \\
\hline \multicolumn{2}{|l|}{ - Нормування входів } & \\
\hline Cигмa GRNN & 5 & \\
\hline Сигма RBF & 5 & \\
\hline Кількість центрів мас & 20 & \\
\hline \multicolumn{3}{|c|}{ Виконати обчислення } \\
\hline
\end{tabular}
інших проектах.

Рис. 3. Інтерфейс програмного рішення

Користувацький інтерфейс програми (рис. 3) розроблено з урахуванням функціональних вимог. Він пе- редбачає використання діалогового режиму взаємодії $з$ користувачем. Користувач може вводити параметри компонентів розробленої структури, зберігати і завантажувати дані з текстових файлів. Для його виконання використано технологію JavaFX.

Результати. Експериментальні дослідження ефективності роботи розробленої нейроподібної структури показали, що найкращу точність прогнозування отримано за значень параметрів: $\delta=4, \sigma=5$ та кількості центрів мас 20. МАРЕ становить $3.2039 \%$. Результати прогнозування порівняно із відомими значеннями функції (8) представлено на рис. 4.

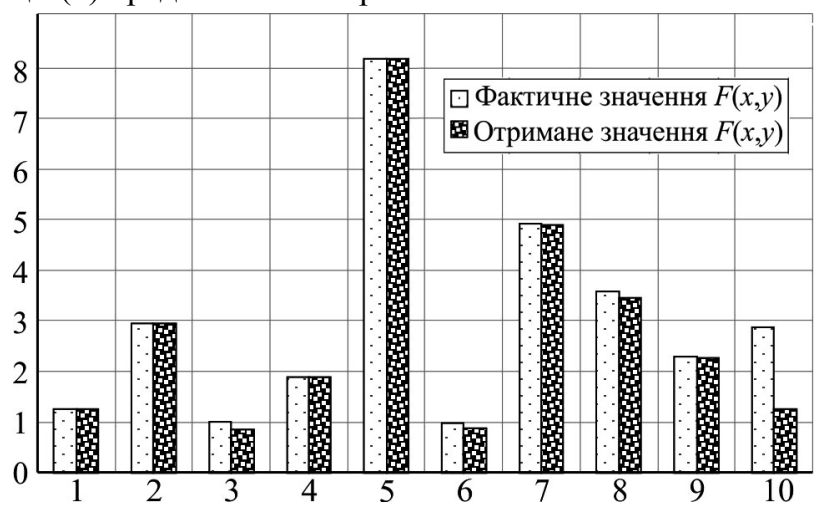

Рис. 4. Результати роботи розробленої системи

Порівняння. Порівняємо отриманий результат з результатами роботи інших методів, а саме: машини опорних векторів, багатошарового перцептрона, нейронною мережею узагальненої регресії. Для отримання результатів роботи зазначених методів використано програму Rapid Miner. Результати проведеного моделювання подано у таблиці.

Таблиця. Порівняння результатів роботи розробленої нейроподібної системи 3 наявними методами

\begin{tabular}{|c|c|c|c|c|}
\hline Метод & $\begin{array}{c}\text { Розробле- } \\
\text { на система }\end{array}$ & $\begin{array}{c}\text { Багатошаро- } \\
\text { вий перцеп- } \\
\text { трон }\end{array}$ & $\begin{array}{c}\text { Мережа уза- } \\
\text { гальненої рег- } \\
\text { ресії }\end{array}$ & $\begin{array}{c}\text { Машина } \\
\text { опорних } \\
\text { векторів }\end{array}$ \\
\hline MАРЕ & $3,2039 \%$ & $10,51 \%$ & $22,41 \%$ & $34,48 \%$ \\
\hline
\end{tabular}

На основі отриманих похибок прогнозування по кожному з методів, можна побачити, що точність їх роботи істотно відрізняється. Розроблена гібридна система обчислювального інтелекту демонструє істотно кращі результати.

Висновки. У роботі описано розроблену авторами нейроподібну систему обчислювального інтелекту для підвищення точності розв'язання задач прогнозування в умовах коротких вибірок даних. Систему побудовано 3 використанням ШНМ узагальненої регресії та гібридної RBF мережі на основі нейроподібних структур МПГП. Подано алгоритмічну процедуру подвоєння входів, проаналізовано способи підбору оптимальних параметрів для їі роботи.

Проведено ряд експериментальних досліджень роботи системи. Ефективність використання розробленої системи підтверджено порівнянням її роботи з наявними методами прогнозування. Розроблена система демонструє найкращі результати роботи.

Застосування розробленої системи та програмного продукту на іiі основі для розв'язання задач прогнозування забезпечило значне підвищення точності, що дає змогу зробити висновок про можливість їі практичного застосування в реальних задачах. Розроблену гібридну нейромережеву систему можна використовувати у ба- 
гатьох галузях національного господарства, зокрема електронній комерції, бізнес-аналітиці, медицині, економіці, криміналістиці, матеріалознавстві тощо

\section{Перелік використаних джерел}

Bandara, K., et al. (2019). Sales Demand Forecast in E-commerce using a Long Short-Term Memory Neural Network Methodology. Retrieved from: https://arxiv.org/abs/1901.04028

Izonin, I., et al. (2018). The Combined Use of the Wiener Polynomial and SVM for Material Classification Task in Medical Implants Production. International Journal of Intelligent Systems and Applications, 10(9), 40-47. https://doi.org/10.5815/ijisa.2018.09.05

Khaikin, S. (2006). Neironnye seti: polnyi kurs. (2nd ed.). (Trans. from English). Moscow: Viliams, 1102 p. [In Russian].

Lin, C. S. (2013). Forecasting and analyzing the competitive diffusion of mobile cellular broadband and fixed broad-band in Taiwan with limited historical data. Econ. Model., 35, 207-213. https://doi.org/10.1016/j.econmod.2013.07.005

Tepla, T. L., et al. (2018). Alloys selection based on the supervised learning technique for design of biocompatible medical materials. Archives of Materials Science and Engineering, 1(93), 32-40.

Tkachenko, R., \& Izonin, I. (2018). Model and Principles for the Implementation of Neural-Like Structures Based on Geometric Data Transformations. In Z. Hu, S. Petoukhov, I. Dychka, M. He (Eds), Advances in Computer Science for Engineering and Education. Advances in Intelligent Systems and Computing, 754, 578-587. Cham: Springer.

Tkachenko, R., Kutucu, H., et al. (2018). Non-iterative Neural-like Predictor for Solar Energy in Libya. In V. Ermolayev, M. C. SuárezFigueroa, A. Ławrynowicz, R. Palma, V. Yakovyna, H. C. Mayr, M. Nikitchenko, \& A. Spivakovsky (Eds), Proc. 14-th Int. Conf. ICT in Education, Research and Industrial Applications, May 14-17, 2018, (pp. 35-45). (Vol. 1). Kyiv. Retrieved from: CEUR-WS.org

Vitynskyi, P., et al. (2018). Hybridization of the SGTM Neural-like Structure through Inputs Polynomial Extension. Proceedings of the 2018 IEEE Second International Conference on Data Stream Mining \& Processing (DSMP), August 21-25, 2018, (pp. 386-391). Lviv: Lviv Polytechnic Publishing House.

P. B. Vitynskyi, R. O. Tkachenko

Lviv Polytechnic National University, Lviv, Ukraine

\section{NURAL-LIKE STRUCTURE FOR FORECASTING IN THE CONDITIONS OF SHORT DATA SAMPLES}

The task of forecasting is one of the priority tasks for the business. The forecasting tools improvements and rapid development of computer facilities attract more and more attention to this issue. Nowadays most managers of leading companies have the possibility to use information systems based on complex mathematics for data analysis. But the problem of understanding the algorithms that are the basis for these information systems and proper selection of the model is still an important task since incorrect predictions can lead to an incorrect decision. The problem is exacerbated in the case of insufficient data amount, in particular, to solve the problems of forecasting demand for a new product or a new service of the organization in e-commerce systems enough data is needed to implement training procedures. However, small data amount leads to inaccurate, incorrect forecasting for existing methods. There is a need to improve the existing and search for new solutions for the task of forecasting in the conditions of short data samples. The paper proposes a new instrument of computational intelligence for the effective solution of the problem. The hybrid neural-like structure for increasing the forecasting accuracy in the conditions of short data samples is described. The system was constructed using the general regression neural network and neural-like structure of the Successive Geometric Transformations Model with RBF layer. The algorithm of system construction based on doubling inputs is developed; the procedure of optimal parameters selection is described. The experimental modeling of the neural network system for solving the forecasting task has shown the high accuracy of its work. The efficiency of using the developed system is confirmed by comparing its work with existing methods such as multilayer perceptron, general regression neural network and support vectors machine. Accuracy measures based on mean absolute percentage error (MAPE) of developed system is 3, 6, 10 times better compared to other methods. The developed system can be used in many areas, including e-commerce, economics, business analytics, etc.

Keywords: forecasting; accuracy increase; generalized regression neural network; radial basis functions network; SGTM neurallike structures. 